\title{
A monolayer of primary colonic epithelium generated on a scaffold with a gradient of stiffness for drug transport studies
}

\author{
Dulan B. Gunasekara ${ }^{1,2}$, Jennifer Speer ${ }^{1}$, Yuli Wang ${ }^{1}$, Daniel L. Nguyen ${ }^{1}$, Mark I. Reed ${ }^{1}$, \\ Nicole M. Smiddy ${ }^{1}$, Joel S. Parker ${ }^{3}$, John K. Fallon ${ }^{4}$, Philip C. Smith ${ }^{4}$, Christopher E. Sims ${ }^{1}$, \\ Scott T. Magness ${ }^{2}$, and Nancy L. Allbritton ${ }^{1,2,{ }^{*}}$ \\ ${ }^{1}$ Department of Chemistry, University of North Carolina at Chapel Hill, NC 27599, USA \\ 2Joint Department of Biomedical Engineering, University of North Carolina at Chapel Hill, NC \\ 27599, USA and North Carolina State University, Raleigh, NC 27607, USA \\ ${ }^{3}$ Department of Genetics and Lineberger Comprehensive Cancer Center, University of North \\ Carolina at Chapel Hill, NC 27514, USA \\ ${ }^{4}$ Division of Pharmacoengineering and Molecular Pharmaceutics, Eshelman School of Pharmacy, \\ University of North Carolina at Chapel Hill, Chapel Hill, North Carolina 27599, USA
}

\section{Abstract}

\begin{abstract}
Animal models are frequently used for in vitro physiologic and drug transport studies of the colon, but there exists significant pressure to improve assay throughput as well as achieve tighter control of experimental variables than can be achieved with animals. Thus development of a primary in vitro colonic epithelium cultured as a high-resistance with transport protein expression and functional behavior similar to that of native colonic would be of enormous value for pharmaceutical research. A collagen scaffold in which the degree of collagen cross-linking was present as a gradient was developed to support the proliferation of primary colonic cells. The gradient of cross-linking created a gradient in stiffness across the scaffold enabling the scaffold to resist deformation by cells. mRNA expression and quantitative proteomic mass spectrometry of cells growing on these surfaces as a monolayer suggested that the transporters present were similar to those in vivo. Confluent monolayers acted as a barrier to small molecules so that drug transport studies were readily performed. Transport function was evaluated using atenolol (a substrate for passive paracellular transport), propranolol (a substrate for passive transcellular transport), rhodamine 123 (Rh123, a substrate for P-glycoprotein) and riboflavin (a substrate for solute carrier transporters). Atenolol was poorly transported with an apparent permeability $\left(\mathrm{P}_{\mathrm{app}}\right)$ of $<5 \times 10^{-7}$ $\mathrm{cm} \mathrm{s}^{-1}$ while, propranolol demonstrated a $\mathrm{P}_{\text {app }}$ of $9.69 \times 10^{-6} \mathrm{~cm} \mathrm{~s}^{-1}$. Rh123 was transported in a
\end{abstract}

\footnotetext{
*Correspondence to: Nancy L. Allbritton, nlallbri@unc.edu. Joint Department of Biomedical Engineering, University of North Carolina, Chapel Hill, North Carolina 27599, USA and North Carolina State University, Raleigh, North Carolina 27695, USA., Tel.: +1-919-966-2291; fax: +1-919-962-2388.

$\dagger$ Electronic supplementary information (ESI) available.

Notes

The authors declare the following competing financial interest(s): N.L.A., Y.W., C.E.S., S.T.M., have a financial interest in Altis Biosystems LLC. The remaining authors disclose no conflicts.

Supporting Information Available

Supplementary data related to this article can be found at http://dx.doi.org/

RNA sequence data presented in this paper can be found in the Gene Expression Omnibus under GSE116541.
} 
luminal direction ( $\mathrm{P}_{\mathrm{app}}$, efflux $/ \mathrm{P}_{\mathrm{app}}$, influx $=7$ ) and was blocked by verapamil, a known inhibitor of $\mathrm{P}$ glycoprotein. Riboflavin was transported in a basal direction and saturation of the transporter was observed at high riboflavin concentrations as occurs in vivo. It is anticipated that this platform of primary colonic epithelium will find utility in drug development and physiological studies since the tissue possesses high integrity and active transporters and metabolism similar to that in vivo.

\section{Introduction}

Two fundamental determinants of drug absorption and excretion in the intestine are epithelial permeability and molecular transport. Handling of drugs in the colon differs significantly from that in the small intestine with the colon possessing greater barrier function, a distinct repertoire of transporters, and a lower surface area. ${ }^{1}$ In the colon, lipophilic xenobiotics readily diffuse across the colonic epithelium, but hydrophilic compounds must be transported. ${ }^{2}$ Transport proteins are located on the luminal-facing and basal membranes of enterocytes where they transport compounds toward the bloodstream or efflux back into the colonic lumen. ${ }^{3}$ Two major classes of transporters are present in the colon, ATP-binding cassette (ABC) transporters and the solute carrier transporters (SLC). Of the $\mathrm{ABC}$ transporter family, p-glycoprotein (P-gp), multidrug resistance-associated protein 2 (MRP2) and breast cancer resistance protein (BCRP) mediate ATP-dependent efflux and play key roles in reducing drug bioavailability and increasing drug resistance of tumor cells. ${ }^{2,4}$ SLC transporters, such as organic cation and anion transporters (OCT and OAT), and peptide transporter 1 (PEPT 1), require an ionic, electrochemical, or concentration gradient for transport and participate in the movement of a variety of substrates including peptides, sugars, and inorganic and organic ions. ${ }^{4-6}$ SLC transporters are important for absorption of charged molecules, particularly cationic pharmaceuticals such as metformin and oxaliplatin.

${ }^{7}$ The study of epithelial permeability and transport using primary colonic intestinal epithelium in an in vitro system would be valuable for understanding the molecular mechanisms of these transport proteins in the colon.

Traditionally, in vitro studies using primary colonic cells have required tissue explants, but these are short lived and challenging to manipulate. ${ }^{8}$ Cell lines derived from colon carcinomas have also been used as these can be maintained for prolonged periods in culture, but suffer from genetic mutations and genome instability. ${ }^{9,10}$ Advances in stem-cell culture techniques have enabled primary intestinal epithelial cells from a variety of mammalian species to be cultured and propagated buried within Matrigel as spheroidal structures known as organoids. ${ }^{11}$ Organoid culture supports proliferation and differentiation of stem cells to generate all of the cell lineages present in the colonic epithelium. ${ }^{11}$ Organoid-based transport assays have been devised to assess P-gp and cystic fibrosis transmembrane conductance regulator (CFTR) function. ${ }^{12,13}$ However, organoids are enclosed structures making it a challenge to access the lumen and the apical surfaces for absorption or transport studies. Additionally, large numbers of transporters are located on the enterocyte apical brush border which is not accessible in an organoid and the addition of drugs to the outwardly facing basal face of the epithelium can lead to inaccurate transport assessment. Development of a monolayer culture of primary cells free of these restrictions would be advantageous. 
Primary cells obtained from freshly isolated colonic crypts or from colonic organoids have been grown as monolayers on membranes with thin coatings of extracellular matrix (ECM).

${ }^{14}$ However, transporter expression and function in these primary cultures have not been well characterized. In addition, the lack of an ECM layer with an appropriate stiffness may cause abnormal adhesion, proliferation and differentiation of the cultured cells. Recently, our group developed a self-renewing monolayer culture of primary colonic epithelium on collagen that enabled stem and progenitor cells to adhere, proliferate and differentiate into all of the expected cell lineages. ${ }^{15}$ However, obtaining a contiguous monolayer with high transepithelial electrical resistance (TEER) as needed for transport studies was challenging since forces exerted by the cells detached the collagen scaffold from the underlying porous membrane. Here we describe a primary colonic epithelial monolayer formed on the planar surface of an ECM scaffold with the appropriate stiffness to support a proliferative colonic epithelial monolayer yet sufficiently rigid to resist cell-based deformation. The monolayers were characterized with regards to parameters critical for drug transport assays, including TEER, permeability, and gene and protein expression by mRNA expression and mass spectrometry, respectively. Functional assays for representative members of the $\mathrm{ABC}$ and SLC transporter families were then validated and examined in the monolayers.

\section{Experimental Section}

\section{Preparation of collagen scaffolds.}

Non-cross-linked collagen scaffold was prepared as described previously by gelling collagen $(1 \mathrm{mg} / \mathrm{mL}, 2.2 \mathrm{~mm}$ thick) in the wells of a standard 6-well plate (effective growth area of membrane $\left.4.2 \mathrm{~cm}^{2}\right) .{ }^{15}$ Collagen scaffolds with a gradient of cross-linking was prepared by adding collagen $(200 \mu \mathrm{L}$ at $1 \mathrm{mg} / \mathrm{mL})$ to individual Transwell inserts (BD Falcon \#353180, transparent PET membrane, $1.6 \times 10^{6}$ pores $/ \mathrm{cm}^{2}$, effective cell culture area of $0.9 \mathrm{~cm}^{2}$ ). Then $1 \mathrm{~mL}$ of PBS was added to upper and lower reservoirs of each Transwell, and the plate was placed at $4^{\circ} \mathrm{C}$ for $30 \mathrm{~min}$. The PBS in the lower reservoir was then replaced with the crosslinking reagents 1-ethyl-3-(3- dimethylaminopropyl)-carbodiimide (EDC, $353 \mathrm{mM}$ ) and Nhydroxysuccinimide (NHS, $88 \mathrm{mM}$ ) in 2-(N- morpholino)ethanesulfonic acid (MES, $4^{\circ} \mathrm{C}$, $1.5 \mathrm{~mL})$. PBS $\left(4^{\circ} \mathrm{C}, 0.5 \mathrm{~mL}\right)$ was added to the upper reservoir. The multi-well plate was maintained at $4^{\circ} \mathrm{C}$ for $40 \mathrm{~min}$ after which time the reservoir fluid was replaced with PBS to remove cross-linking reagents (Supporting Information). The scaffold was immersed in deionized water to leach out EDC and NHS and sterilized with 70\% ethanol for $5 \mathrm{~min}$, washed with PBS, and were then stored in PBS for a minimum of one week before usage to insure removal of residual cross-linking reagents.

\section{Monolayer culture of colonic epithelial cells.}

Colonic epithelial cells were isolated from the crypts of mice expressing cytomegalovirus enhancer plus chicken actin promoter (CAG)-DsRed or wild- type (WT) mice as described previously. ${ }^{15,16}$ Propagation of monolayers possessing colonic stem cells was previously described and is briefly summarized in the Supporting Information. ${ }^{15}$ To generate contiguous monolayers, cells from a monolayer culture were suspended in EM and plated on gradient cross-linked scaffolds $\left(900,000\right.$ cells $\left./ \mathrm{cm}^{2}\right)$. Dead cells on the surface of the monolayers were removed each day starting at day 2 by gently pipetting the medium up and 
down $\times 5$ using a $1 \mathrm{~mL}$ pipette followed by replacement of the media. The monolayer visibly covered the entire surface of the scaffold by 3-5 days. To compare cell growth on the gradient cross-linked scaffolds to the non cross-linked collagen scaffolds, cells $(900,000$ cells $/ \mathrm{cm}^{2}$ ) were added to 12 -well Transwell plates containing gradient cross-linked scaffolds and 24-well Transwell plates with neutral collagen scaffolds. By day 2, monolayers of cells were visible on both scaffolds. Cells were then fixed using $4 \%$ paraformaldehyde and stained using Hoechst 33342 to calculate coverage.

\section{Measurement of TEER.}

The resistance between the upper (luminal, U) and lower (basal, B) surfaces of confluent monolayers cultured on gradient cross-linked scaffolds was measured using an EVOM2 epithelial Volt/Ohm meter (World Precision Instruments, Sarasota, FL). The resistance was measured with EM in the upper and lower reservoirs on each side of the scaffold $(n=3)$. The resistance with a monolayer of cells was corrected by subtracting the average resistance of scaffolds without cells and normalized by multiplying the effective scaffold surface area $\left(0.9 \mathrm{~cm}^{2}\right)$ to provide a TEER in units of $\Omega \mathrm{cm}^{2}$.

\section{Measurement of the permeability of confluent cell monolayers.}

The permeability of the confluent monolayers to LY, a water-soluble, small molecular weight dye (M.W. $442.2 \mathrm{~g} / \mathrm{mol}$ ) was assessed since this molecule is not actively transported by the colonic epithelium. LY $(500 \mu \mathrm{M}, 0.5 \mathrm{~mL})$ in EM was added to the upper reservoir of a confluent monolayer on a collagen scaffold in a Transwell insert. The lower reservoir was filled with EM (1.5 mL). Fluid was sampled $(80 \mu \mathrm{L})$ from the lower reservoir over $6 \mathrm{~h}$. An identical amount of EM was added back to the lower reservoir after each sampling. The amount of LY in the lower reservoir was quantified by fluorescence (Spectramax M5, Molecular Devices, ex: $428 \mathrm{~nm}$, em: $520 \mathrm{~nm}$ ). The apparent permeability $\left(\mathrm{P}_{\mathrm{app}}\right)$ of LY diffusion was calculated at $6 \mathrm{~h}$ after addition of the analyte to one of the reservoirs since $\mathrm{P}_{\text {app }}$ of $\mathrm{LY}$ remained within $10 \%$ of this value $3 \mathrm{~h}$ after initiating the experiment: ${ }^{17} \mathrm{P}_{\mathrm{app}}$ was calculated as follows: $\mathrm{P}_{\mathrm{app}}=(\mathrm{dQ} / \mathrm{dt})\left(1 / \mathrm{A} \mathrm{C}_{0}\right)\left(\mathrm{cm} \mathrm{s}^{-1}\right)$

Where $\mathrm{dQ} / \mathrm{dt}$ is the steady state flux towards the lower reservoir, $\mathrm{C}_{0}$ is the initial concentration in the upper reservoir and A is the scaffold's surface area $\left(0.9 \mathrm{~cm}^{2}\right)$.

\section{mRNA expression analysis.}

Cells grown as confluent monolayers were collected at days $3\left(526 \pm 56 \Omega \mathrm{cm}^{2}\right), 4(623 \pm 15 \Omega$ $\left.\mathrm{cm}^{2}\right)$ and $5\left(407 \pm 53 \Omega \mathrm{cm}^{2}\right)$. Each sample consisted of the cells from a single insert of a 12well Transwell. Independent replicates (3) were performed for each data point. Isolated crypts from the same mouse from which the monolayers were established were used for comparisons. Total RNA was isolated using MicroRNAqueous Kit (Ambion). RNA quality was assessed by bioanalyzer, and all samples demonstrated an RNA Integrity Number (RIN) greater than 8.0. Illumina sequencing libraries were generated from this RNA using SMARTer ${ }^{\circledR}$ Stranded Total RNA Sample Prep Kit with Illumina indexes using manufacture protocols. The quality of libraries was evaluated by bioanalzyer, all libraries passed quality control, and were pooled according to manufacturer specifications for sequencing on an Illumina NextSeq 500 instrument with a single end 75 bp high output kit. Data was 
processed through computational piplines described in the GEO entry. Each sample was sequenced to a depth between $\sim 2 \times 10^{6}$ to $\sim 6 \times 10^{6}$ reads/sample (ave $=4.1 \times 10^{6}+/-1.4 \times$ $\left.10^{6}\right)$. The number of genes detected per sample ranged from 12,000 to 14,500 genes/sample $($ ave $=14,001+/-687)$.

To evaluate the transporter expression, global level mRNA expression of both SLC and ABC transporters at $1 \%$ false discovery rate (FDR) over time was performed. FDR accounts for false expression within the significant genes and therefore provides a more accurate statistical result. ${ }^{18}$ Here we set the FDR to $1 \%$ such that the false positive rate is $\unlhd$ gene out of 100 .

\section{Measurement of transporter protein expression by mass spectrometry.}

Quantitative targeted absolute proteomic conducted by selected reaction monitoring mass spectrometry (QTAP SRM) was used to determine whether selected transporter proteins were detectable within the cell monolayers and fresh crypts. A stable isotope-labeled reference proteotypic peptide (standard, Table S2) at a known concentration was added to the membrane fraction sample prior to LC-MS/MS analysis. ${ }^{19}$ Absolute quantification was based on the ratio between the SRM signals (Table S2) of the analyte and that of the standard peptide. Using the known concentration of the standard added to the sample, the absolute concentration of the analyte was directly calculated through a linear correlation. Samples for analysis by QTAP SRM were prepared from 12 monolayers grown on 12-well Transwell inserts pooled and homogenized in hypotonic buffer $(1 \mathrm{M}$ tris $\mathrm{HCl}, 1 \mathrm{M} \mathrm{NaCl}$, $\left.0.15 \mathrm{M} \mathrm{MgCl}_{2}\right)$. The samples were centrifuged $\left(10,000 \mathrm{rcf}\right.$ at $\left.4^{\circ} \mathrm{C}\right)$, supernatant was taken off and the protein was pelleted by ultracentrifugation $\left(55,000 \mathrm{rcf}\right.$ at $\left.4^{\circ} \mathrm{C}\right)$. The resulting protein pellet representing the membrane fraction was re-suspended in fresh PBS and analyzed. The average TEER of samples was $180 \pm 20 \Omega \mathrm{cm}^{2}$ (day 2), $1140 \pm 140 \Omega \mathrm{cm}^{2}$ (day 4), and $320 \pm 20 \Omega \mathrm{cm}^{2}$ (day 6). The TEER dropped on day 6 as differentiated cells began to reach the end of their life span and die.

\section{Measurement of transport across the monolayers.}

For all transport studies, monolayers grown for 4-5 days with TEER $>300 \Omega \mathrm{cm}^{2}$ were used. A mix of atenolol (ATL, $10 \mu \mathrm{M}$ ) and propranolol (PPL, $10 \mu \mathrm{M}$ ) was added to the upper reservoir (apical face of the monolayer). To assess transport, fluid from the lower reservoir was collected at $3 \mathrm{~h}$. The concentration of ATL and PPL in the lower reservoir were determined using HPLC-triple quadrupole mass spectrometry (MS/MS, PESciex API 3000, AB Sciex, equipped with Shimadzu LC System) with multiple reaction monitoring (MRM). ${ }^{20}$ A C- 18 analytical column with linear gradient from $100 \%$ water with $1 \%$ formic acid to $80 \%$ acetonitrile with $1 \%$ formic acid over $8 \mathrm{~min}(0.3 \mathrm{~mL} / \mathrm{min})$ was used for the separation. Metoprolol was used as an internal standard. Eluted species were subjected to electrospray ionization (positive mode) and transitions of $267.2 / 190$ (m/ $\mathrm{z}$ of precursor ion/product ion) for atenolol, 260.2/116.1 for propranolol, and 268.2/116.1 for metoprolol were monitored.

To measure the activity of the p-gy transporter, Rh123 $(10 \mu \mathrm{M})$ in EM medium was added to the lower $(1.5 \mathrm{~mL})$ or upper $(0.5 \mathrm{~mL})$ reservoir. The opposing reservoir was filled with EM ( $0.5 \mathrm{~mL}$, upper or $1.5 \mathrm{~mL}$, lower). After $2 \mathrm{~h}, 80 \mu \mathrm{L}$ of media was collected from the 
appropriate receiving reservoir and Rh123 accumulation was determined by measuring Rh123 fluorescence (excitation: $490 \mathrm{~nm}$, emission: $529 \mathrm{~nm}$ ). The efflux over influx ratio was calculated considering the Rh123 diffusion in respective blank scaffolds. In experiments to confirm that p-gy was the transporter responsible for Rh123 transport, the p-gy inhibiter verapamil $(200 \mu \mathrm{M})$ was incubated with the monolayer for $1 \mathrm{~h}$ prior to addition of Rh123. Then Rh123 $(10 \mu \mathrm{M})$ with verapamil $(200 \mu \mathrm{M})$ in EM was added to the lower reservoir and fluid was collected from the upper reservoir followed by quantification of the Rh123 concentration in the medium. The duration of the inhibition assay was $2 \mathrm{~h}$ similar to that of the Rh123 transport assay.

To measure the activity of the SLC52A3 transporter, riboflavin (1 or $5 \mu \mathrm{M}$ in EM) was added to the upper reservoir and the fluid in the lower reservoir was sampled at 3 and $24 \mathrm{~h}$. Riboflavin was measured using high performance liquid chromatography (HPLC, Agilent 1100 Series) with fluorescence detection (ex: $368 \mathrm{~nm}$, em: $515 \mathrm{~nm}$ ) and quantified against a calibration curve $(250 \mathrm{nM}$ to $2 \mu \mathrm{M})$. A C-18 analytical column was employed with a gradient of $100 \%$ water to $100 \%$ acetonitrile over $10 \mathrm{~min}(0.5 \mathrm{~mL} / \mathrm{min})$.

\section{Statistics.}

Gene expression profiles estimated from mRNA-seq were compared across the 2-, 3-, and 5day time points, then contrasted against the crypt samples. Initial evaluation of these profiles was performed using principal component analysis and hierarchical clustering to assess quality and overall experimental signal. The hypothesis regarding differential expression across time was tested with DESeq $2^{21}$ with time points encoded as three categories to test the null hypothesis that the mean expression is the same across these conditions. Parametric p-values from DESeq2 were adjusted for multiple comparison using the method of Benjamini and Hochberg (1995). ${ }^{22}$ The resulting adjusted $\mathrm{p}$ - values $\left(\mathrm{P}_{\mathrm{adj}}\right)$ for individual comparisons were represented using symbols in the figures. For the remaining statistical comparisons, one-way ANOVA with Tukey's comparisons were used for multiple samples. For comparison of two groups, a two-tailed t-test was used. These statistical tests were performed at a significance level of 0.05 using GraphPad Prism (GraphPad Software, Inc. La Jolla, CA). The $\mathrm{P}_{\mathrm{adj}} / \mathrm{P}$ were represented as follows in the figures: $*$ for $\mathrm{P} / \mathrm{P}_{\mathrm{adj}}<0.05,{ }^{* *}$ or $\mathrm{I}$ for $\mathrm{P} / \mathrm{P}_{\mathrm{adj}}<0.01,{ }^{* * *}$ or $\|$ for $\mathrm{P} / \mathrm{P}_{\mathrm{adj}}<0.001,{ }^{* * * *}$ or $¥$ for $\mathrm{P} / \mathrm{P}_{\mathrm{adj}}<0.0001$. Unless stated otherwise, the average and standard deviation (SD) of the data points were used to display the data (average $\pm \mathrm{SD}$ ).

\section{Results and Discussion}

\section{Generation of collagen scaffolds with a stiffness gradient.}

We previously demonstrated that colonic epithelial cells could be cultured on a collagen scaffold to create a self-renewing monolayer of primary intestinal cells. ${ }^{15}$ However, when these cells were cultured on a collagen scaffold overlaid on a porous membrane instead of a solid polystyrene surface, the scaffolds contracted over time most likely due to contractile forces generated by the cells (Figure 1A) (n=3 scaffolds). A scaffold with an upper surface sufficiently soft to enable robust cell attachment and proliferation, yet with adequate rigidity to resist cellular forces would be optimal for culture of the colonic epithelial cells. Small 
molecules such as EDC and NHS are expected to require on average several hours to diffuse through the 2.2-mm-thick collagen scaffold. ${ }^{23}$ Thus, selective addition of these cross-linking reagents to the lower surface of the collagen scaffold might yield a region of sufficient stiffness at its base to resist deformation, yet leave the upper surface with properties suitable to support cell attachment and proliferation. To test this possibility, EDC and NHS were added to the lower reservoir of a Transwell containing a non-cross- linked collagen scaffold while buffer alone was added to the upper reservoir (Figure 1C). The upper surface of the scaffolds cross-linked with the reagents in the lower reservoir demonstrated a stiffness of $395 \pm 370 \mathrm{~Pa}$ in which $18 \%$ of measurements were $<100 \mathrm{~Pa}$. While the overall average was higher than that of non-cross-linked collagen ( $21 \pm 12 \mathrm{~Pa}$, $\mathrm{n}=5$ scaffolds), the stiffness was significantly less than that of the scaffold surface in direct contact with the cross-linking reagents (see below). The pore size of the collagen on the upper surface $(350 \pm 120 \mathrm{~nm})$ and of neutral collagen $(390 \pm 240 \mathrm{~nm}$ ) was also similar (Figure 1D,E). When the cross-linking reagents were added to the upper reservoir, the stiffness of the upper surface of the collagen exposed directly to EDC/NHS was significantly greater still (2391 $\pm 2215 \mathrm{~Pa}, \mathrm{p}<0.0001, \mathrm{n}=5$ scaffolds). These data suggested that a gradient of cross-linking or stiffness might exist through the scaffold with the greatest degree of cross-linking in the collagen nearest the reservoir containing EDC/NHS. Forming a gradient in a similar manner using a readily visualized Alexa Fluor ${ }^{\text {TM }} 594$ NHS suggested that such a gradient was feasible (Figure S1). When primary colonic epithelial cells were cultured on the upper surface of collagen crosslinked from the lower reservoir, the cells attached and proliferated and did not deform the collagen (Figure 1B, Figure S2).

\section{Characterization of primary colonic epithelial cell growth on the gradient cross-linked scaffold.}

Although the cells attached to the gradient cross-linked scaffold, it was important to understand whether the primary cells were comparable to that previously described for growth on non-cross-linked collagen. ${ }^{15}$ The rate of cell growth on the gradient cross-linked scaffold (cross-linked from the lower reservoir) was compared to that on non-cross-linked collagen by measuring the percentage of scaffold surface area coverage over time. At day 2, the cells on the gradient cross-linked scaffold grew more slowly than those on the non-crosslinked scaffold (Figure 1F). By day 5, however, the cells on the gradient cross-linked scaffold spanned the entire scaffold surface $\left(0.9 \mathrm{~cm}^{2}\right)$ with the cells evenly distributed and tightly packed (Figure 2A, Figure S2). A cross-section through the cells and scaffold demonstrated a single layer of cells with an average inter-nuclear distance of $9.7 \pm 1.8 \mu \mathrm{m}$ (n $=18$ cells $)$ similar to that previously reported in vivo $(8.0 \pm 2.3 \mu \mathrm{m}) .{ }^{24}$ The monolayer of cells also exhibited an appropriate basal to luminal polarization (Figure 2B). Actin, known to be enriched in the brush border, was concentrated at the luminal surface where the microvilli reside in contact with the overlying aqueous medium. ${ }^{25}$ Integrin $\beta 4$, a ligand for laminin in the ECM, was located along the basal aspect of the cells adjacent to the scaffold. 15 The tight junction proteins (E-cadherin, zonula occludens-1 (ZO-1) were at high density at the cell-cell borders as in vivo (Figure 2C, D). ${ }^{15,25}$ 


\section{Identification of cell types present within the monolayer.}

mRNA expression analysis suggested that the cells of the monolayer became increasingly differentiated as they reached confluency (Figure S3,4). However, it was important to confirm that the synthesis of proteins characteristic of differentiated cells (Muc2 in goblet cells and ALP in enterocytes) also increased over time since it is the differentiated cells that participate in transport of molecules. Absorptive enterocytes that are responsible for transport across the colonic epithelium produce ALP and were readily identified at day 3 of culture. ${ }^{26}$ By day 5 , the monolayer exhibited significantly increased ALP compared to day 4 and significantly decreased EdU incorporation compared to day 2 suggesting that the monolayers were increasingly comprised of differentiated cells (Figure 2E, Figure S3,4).

\section{Measurement of cellular junction gene expression in the monolayers.}

Colonic epithelial cells form a high resistance barrier enabling the cells transport molecules even against a concentration gradient. ${ }^{27}$ Tight junctions are the gatekeepers for diffusing molecules while adherens junctions are associated with initiation of contacts between cells. ${ }^{28}$ For all monolayer culture times, mRNA expression of most genes encoding for tight and adherens junction proteins was at comparable or greater levels relative to that found in fresh crypts (Figure 3A). ${ }^{27,29}$ The expression of these critical genes for colonic barrier function in the epithelium suggested that the monolayers might have cell-cell borders of sufficient integrity to act as a barrier to ions and other small molecules.

\section{Measurement of monolayer TEER and permeability.}

The ability of the confluent monolayer grown on the gradient cross-linked scaffold to act as a barrier to the movement of ions and larger molecules was assessed by measuring both the TEER and the perm0ability of lucifer yellow (LY). TEER was measured over time as the monolayers grew to confluency. On day 2 when the cells were present largely in isolated patches, the TEER was not significantly different from that of the scaffold without cells $\left(170 \pm 10 \Omega \mathrm{cm}^{2}\right.$ vs. $160 \pm 10 \Omega \mathrm{cm}^{2}, \mathrm{n}=5$ replicates from 1 male mouse, $\left.\mathrm{p}=0.128\right)$. By days $3-5$, many of the cell patches had expanded and merged and the TEER increased significantly to $240 \pm 140 \Omega \mathrm{cm}^{2}, 440 \pm 80 \Omega \mathrm{cm}^{2}$, and $390 \pm 60 \Omega \mathrm{cm}^{2}$ for days $3-5$, respectively (Figure S6A). To evaluate the reproducibility of high-TEER monolayer generation, 18 monolayers were grown on cross-linked scaffolds. Seventeen (94\%) produced monolayers with TEER $>290 \Omega \mathrm{cm}^{2}$. However, the average TEER values were $>390 \Omega \mathrm{cm}^{2}$ for all animals demonstrating formation of monolayers with excellent barrier integrity (Figure S6B). The most commonly used intestinal cell type used for barrier/permeability studies is Caco-2, a human colonic adenocarcinoma cell line that typically achieves a TEER of 420 to $660 \Omega \mathrm{cm}^{2}$ when grown to confluency and differentiated over a 3-week period to an enterocyte-like cell. ${ }^{30}$ Overall, the TEER value for the mouse monolayers suggested that these tissues would be of sufficient integrity for small-molecule transport studies.

Permeation of a small fluorescent non-transported molecule such as LY was used to further evaluate the integrity of the monolayers. LY is not a substrate for intestinal transporters. ${ }^{17,30}$ The apparent permeability $\left(\mathrm{P}_{\mathrm{app}}\right)$ of $\mathrm{LY}$ through the cell monolayer (days 4-5 of culture) was measured over time and compared to that of the scaffold alone (Figure 3C). Average $\mathrm{P}_{\mathrm{app}}$ of LY reached a steady state flux of $2.44 \pm 1.64 \times 10^{-7} \mathrm{~cm} \mathrm{~s}^{-1}$ for monolayers with a 
TEER > $300 \Omega \mathrm{cm}^{2}(\mathrm{n}=6)$ at $3 \mathrm{~h}$ after placement of LY into the upper reservoir. While $\mathrm{P}_{\text {app }}$ for LY is a more accurate indicator than TEER of monolayer permeability to small, nontransported molecules, $\mathrm{P}_{\text {app }}$ is more challenging to measure than TEER especially when handling the fragile monolayers of primary-cells. For this reason, we sought to correlate the TEER with $\mathrm{P}_{\text {app }}$ for LY so that the TEER could be used as a surrogate measure when assessing the suitability of monolayers in drug transport assays. $\mathrm{P}_{\text {app }}$ for LY was measured for monolayers at varying TEER values (Figure 3D). All monolayers with a TEER $>300 \Omega$ $\mathrm{cm}^{2}$ demonstrated a $\mathrm{P}_{\text {app }}<4.5 \times 10^{-7} \mathrm{~cm} \mathrm{~s}^{-1}(\mathrm{n}=6)$ for LY. A $\mathrm{P}_{\text {app }}>1 \times 10-6 \mathrm{~cm} \mathrm{~s}-1$ is typically characterized as "leaky" and not suitable for transport assays. ${ }^{17}$ Thus, based on the measured TEER and $\mathrm{P}_{\mathrm{app}}$ values, the confluent monolayers comprised of primary, murine colonic epithelium possessed sufficient integrity for assay of molecular transport.

\section{mRNA expression of transporters in the confluent monolayers.}

The colon is known to have an active transport system in addition to that required for the reabsorption of water via osmosis following salt transport. mRNA expression analysis was performed for the confluent monolayers to identify which transporters might be present in these primary cell cultures. Transporter gene expression of both SLC and ABC transporters between day 5 and crypts $v s$. day 3 and crypts was compared. For ABC transporters, 8 transporters in monolayers cultured for 5 days were changed at 1\% FDR. Seven of eight demonstrated concordant increase with day 5 monolayers and crypts $v$ s. day 3 monolayers (Figure S7A). Within SLC transporters, 59 transporters in monolayers cultured for 5 days were changed at $1 \%$ FDR. Of these SLC transporters, 51 of 59 demonstrated concordant increase when comparing day 5 monolayers and crypts vs. day 3 monolayers (Figure S7B). Overall, 59 SLC and ABC transporters are concordantly increased and 9 were concordantly decreased when comparing day 5 and crypts $v s$. day 3 . As the culture time for the monolayer increased, the cells more closely resembled in vivo tissue with respect to the transporters examined.

\section{Protein expression of transporters in the confluent monolayers.}

The 5-day confluent monolayers were examined for the protein expression of a subset of the clinically relevant transporters identified by RNA expression (Table 1). P-gp, BCRP, MRP1, MRP3 transporters and the NaK ATPase ion channel peptides were identified by mass spectrometry (Figure S8, Table S1). The identified proteins exemplified a range of different transporter types and transport mechanisms. P-gp and BCRP are efflux secretory transporters present on the apical membrane of the cell and transport molecules from the cytosol into the colonic lumen. ${ }^{4}$ MRP1 and MRP3 are efflux absorptive transporters that are located on the basal membrane of the cells moving molecules from the interstitial (or basal) space into the cytosol. ${ }^{4} \mathrm{P}$-gp, MRP1/3 and BCRP all belong to the family of ATP-binding cassette $(\mathrm{ABC})$ transporters and are energy dependent. ${ }^{2}$ These transporters play an important role in drug absorption and many drugs are transported by more than one of these proteins. For example, digoxin, paclitaxel and dexamethasone are substrates for P-gp; doxorubicin, topotecan and methotrexate are BCRP substrates; pravastatin and irinotecan are MRP1 substrates; vincristine, etoposide and methotrexate are substrates for MRP3. ${ }^{31}$ 
The levels of the transporters were also examined in crypts freshly isolated from mice for comparison to that in the monolayers. On day 2 of monolayer culture, the transporter proteins possessed an abundance well below that of the fresh crypts. However, as the monolayers matured and transitioned to the enterocyte lineage (days 4 and 6), most of the transporter levels approached that found in the crypts (Table 1, Figure S8). Overall, protein production of these transporters was consistent with the measured mRNA expression as well as the protein production and mRNA expression of fresh crypts. These data suggested that amount of the transporters in the confluent monolayers were representative of that found in vivo. Taken together, these transporter protein expression data demonstrated that multiple clinically important transporters were present in the monolayer and suggested that these colonic tissues might be suitable for functional transport assays.

\section{Measurements of para- and transcellular transport.}

ATL and PPL are beta-blockers used to treat hypertension and are also commonly used as substrates for para- and transcellular transport (ATL-paracellular, PPL-transcellular). ${ }^{32,33}$ The high $\mathrm{P}_{\mathrm{app}}$ of PPL measured for the day-5 monolayers suggested transcellular transport for this drug as highly permeable compounds exhibit $\mathrm{P}_{\text {app }}>2 \times 10^{-6} \mathrm{~cm} \mathrm{~s}^{-1}$ (Figure 4A). ${ }^{17}$ The $\mathrm{P}_{\mathrm{app}}$ of ATL indicated a low permeability similar to that of LY (Figure 4A). The reported permeability of ATL and PPL for Caco-2 cells are $0.2-1\left(\times 10^{-6}\right) \mathrm{cm} \mathrm{s}^{-1}$ and 4-25 $\left(\times 10^{-6}\right) \mathrm{cm} \mathrm{s}^{-1}$ respectively; therefore, $\mathrm{P}_{\mathrm{app}}$ values measured in our colonic monolayers are within the range of reported permeability values of Caco-2 cells. ${ }^{32,34,35}$ While the $\mathrm{P}_{\mathrm{app}}$ of PPL for the colonic monolayers and Caco-2 was similiar to that estimated for in vivo tissue, the $\mathrm{P}_{\text {app }}$ of ATL for neither the colonic monolayers nor the Caco- 2 cells was similar to that estimated for in vivo colon (Supporting Information). ${ }^{32-35}$ The source of this difference is unclear and may be due to differences in the intercellular connections between the systems or challenges in measuring in vivo permeabilities. Never-the-less these data do support the presence of a tight barrier in these murine colonic monolayers and selective absorption of compounds through the transcellular route.

\section{Measurement of P-gp-mediated transport in the monolayers.}

To determine whether the transporter proteins identified were functional, the ability of P-gp to transport Rh123 across the monolayer was measured. ${ }^{36} \mathrm{P}_{\text {app }}$ from the lower to upper reservoir $\left(\mathrm{P}_{\mathrm{app}}, \mathrm{B}\right.$ to $\left.\mathrm{U}\right)$ was $7 \times$ greater than that from the upper to lower reservoir ( $\mathrm{P}_{\text {app }, \mathrm{U} \text { to B }}$ ) confirming that Rh123 was preferentially transported into the upper or luminal compartment as described previously (Figure $4 \mathrm{~B}$ ). ${ }^{36} \mathrm{~A} \mathrm{P}_{\text {app, }, \mathrm{B} \text { to } \mathrm{U}} / \mathrm{P}_{\text {app }, \mathrm{U}}$ to B exceeding 2 is characteristic of efflux secretory transport. ${ }^{37}$ The $\mathrm{P}_{\text {app, }} \mathrm{B}$ to $\mathrm{U} / \mathrm{P}_{\text {app }}, \mathrm{U}$ to $\mathrm{B}$ value of 7 is however lower than that typically reported in the literature for Caco-2 tumor cells ( $\mathrm{P}_{\text {app, }} \mathrm{B}$ to U $/ \mathrm{P}_{\text {app, } \mathrm{U} \text { to }} \mathrm{B}>10$ ). ${ }^{36}$ Verapamil, another substrate for P-gp, should act as a competitive inhibitor of Rh123 when co- added with Rh123 providing confirmation that the observed movement of Rh123 is due to P-gp activity rather than another transporter. ${ }^{38}$ In the presence of verapamil, $\mathrm{P}_{\mathrm{app}}$ for Rh123 decreased significantly (Figure 4B, $\mathrm{p}<0.001$ ). These data support that active $\mathrm{P}$-gp is present in these primary colonic monolayers, and the monolayers may serve as a platform for the investigation of drug-drug interactions involving P-gp. 


\section{Measurement of SLC52A transporter activity in the monolayers.}

Riboflavin (vitamin B2) is an important cofactor for redox intermediate flavin coenzymes (e.g. FAD and FAM) which play a key role in the metabolism of carbohydrates, amino acids and lipids. ${ }^{39,40}$ SLC52A transports riboflavin from the gut lumen across the epithelium and mutations in the SLC52A can lead to riboflavin deficiency. ${ }^{39,40}$ The mRNA expression data suggested that SLC transporters might be present in the colonic monolayers including SLC52A2 and SLC52A3. To demonstrate the absorption of important dietary compounds through the colonic monolayers, riboflavin transport was assayed by adding riboflavin ( 1 or $5 \mu \mathrm{M})$ to the upper reservoir, but not the lower reservoir. The fractional absorption of riboflavin was measured over time (Figure 4C). The fractional riboflavin accumulation was significantly higher when the concentration was $1 \mu \mathrm{M}$ compared to $5 \mu \mathrm{M}$ at both $3 \mathrm{~h}$ and 24 h. The riboflavin transporter is known to saturate at high riboflavin concentrations. ${ }^{41,42}$ These data demonstrate active transport of a variety of molecules across the primary colonic monolayers enabling the tissues to serve as a platform for exploration and screening of dietary compound and drug absorption.

\section{Conclusions}

A gradient cross-linked collagen scaffold was developed to generate confluent monolayers of primary murine colonic epithelial cells. A gradient of amine-based crosslinking provided a scaffold surface that supported colonic cell adhesion, proliferation and generation of confluent monolayers with high TEER in a reproducible manner. The cross-linking strategy further solved the challenge of cell- mediated collagen contraction. The planar geometry of the platform produced in this work enabled ready access to both upper (luminal) and lower (basal) surfaces, a distinct advantage over organoid systems. Global mRNA expression profiles of colonic monolayers showed gene expression of monolayers by day 5 that highly correlated with native crypt tissue with differentiated and functional enterocytes. The monolayers possessed excellent integrity as evidenced by their high TEER and impermeability to LY. Many of the ABC and SLC family transporters in crypts were also expressed in day 5 monolayers and the monolayers were successfully used to demonstrate drug and nutrient transport and absorption using para- and passive transcellular, P-gp and solute carrier-based transporter specific substrates. The low $\mathrm{P}_{\text {app }}$ value of paracellular transport measurements indicated tight cellular contacts in our model. Further, P-gpmediated transport demonstrated that the monolayers extruded compounds, an important demonstration for future drug inhibition or drug-drug interaction assays. Riboflavin absorption through the riboflavin transporter provided evidence of colonic nutrient absorption utilizing SLC-based transporters. These features enable the colonic monolayers to be employed for drug transport, toxicity and screening assays.

\section{Supplementary Material}

Refer to Web version on PubMed Central for supplementary material. 


\section{Acknowledgements}

Research reported in this publication was supported by the National Institutes of Health under award number R01DK109559. The authors thank Ian Williamson for coordinating the procurement of mouse colons, Carrie Donley for help with AFM measurements, Jodi E. Stone for HPLC analysis and Matthew DiSalvo for automated fluorescence imaging. This work was performed in part at the Chapel Hill Analytical and Nanofabrication Laboratory, CHANL, a member of the North Carolina Research Triangle Nanotechnology Network, RTNN, which is supported by the National Science Foundation, Grant ECCS-1542015, as part of the National Nanotechnology Coordinated Infrastructure, NNCI. Also, authors thank UNC Chemistry mass spectrometric core laboratory for the sample analysis.

\section{References}

(1). Tannergren C; Bergendal A; Lennernäs H; Abrahamsson B Toward an Increased Understanding of the Barriers to Colonic Drug Absorption in Humans: Implications for Early Controlled Release Candidate Assessment. Mol. Pharm 2009, 6, 60-73. [PubMed: 19183105]

(2). Chan LMS; Lowes S; Hirst BH The ABCs of Drug Transport in Intestine and Liver: Efflux Proteins Limiting Drug Absorption and Bioavailability. Eur. J. Pharm. Sci 2004, 21, 25-51. [PubMed: 14706810]

(3). Kunta JR; Sinko PJ Intestinal Drug Transporters: In Vivo Function and Clinical Importance. Curr. Drug Metab 2004, 5, 109-124. [PubMed: 14965254]

(4). Hillgren K; Keppler D; Zur A; Giacomini K; Stieger B; Cass C; Zhang L Emerging Transporters of Clinical Importance: An Update from the International Transporter Consortium. Clin. Pharmacol. Ther 2013, 94, 52-63. [PubMed: 23588305]

(5). Lin L; Yee SW; Kim RB; Giacomini KM SLC Transporters as Therapeutic Targets: Emerging Opportunities. Nat. Rev. Drug Discov 2015, 14, 543-560. [PubMed: 26111766]

(6). Keogh J; Hagenbuch B; Rynn C; Stieger B; Nicholls G Chapter 1 Membrane Transporters: Fundamentals, Function and Their Role in ADME. In Drug Transporters: Volume 1: Role and Importance in ADME and Drug Development; The Royal Society of Chemistry, 2016; Vol. 1, pp 1-56.

(7). Giacomini KM; Huang S-M; Tweedie DJ; Benet LZ; Brouwer KLR; Chu X; Dahlin A; Evers R; Fischer V; Hillgren KM; et al. Membrane Transporters in Drug Development. Nat. Rev. Drug Discov 2010, 9, 215-236. [PubMed: 20190787]

(8). Clarke LL A Guide to Ussing Chamber Studies of Mouse Intestine. Am. J. Physiol. - Gastrointest. Liver Physiol 2009, 296, G1151-G1166. [PubMed: 19342508]

(9). Castle JC; Loewer M; Boegel S; de Graaf J; Bender C; Tadmor AD; Boisguerin V; Bukur T; Sorn $\mathrm{P}$; Paret C Immunomic, Genomic and Transcriptomic Characterization of CT26 Colorectal Carcinoma. BMC Genomics 2014, 15, 190. [PubMed: 24621249]

(10). Sun H; Chow EC; Liu S; Du Y; Pang KS The Caco-2 Cell Monolayer: Usefulness and Limitations. Expert Opin. Drug Metab. Toxicol 2008, 4, 395-411. [PubMed: 18433344]

(11). Sato T; Stange DE; Ferrante M; Vries RGJ; van Es JH; van den Brink S; van Houdt WJ; Pronk A; van Gorp J; Siersema PD; et al. Long-Term Expansion of Epithelial Organoids From Human Colon, Adenoma, Adenocarcinoma, and Barrett's Epithelium. Gastroenterology 2011, 141, 1762-1772. [PubMed: 21889923]

(12). Mizutani T; Nakamura T; Morikawa R; Fukuda M; Mochizuki W; Yamauchi Y; Nozaki K; Yui S; Nemoto Y; Nagaishi T Real-Time Analysis of P-Glycoprotein-Mediated Drug Transport across Primary Intestinal Epithelium Three-Dimensionally Cultured in Vitro. Biochem. Biophys. Res. Commun 2012, 419, 238-243. [PubMed: 22342245]

(13). Dekkers JF; Wiegerinck CL; de Jonge HR; Bronsveld I; Janssens HM; de Winter-de Groot KM; Brandsma AM; de Jong NWM; Bijvelds MJC; Scholte BJ; et al. A Functional CFTR Assay Using Primary Cystic Fibrosis Intestinal Organoids. Nat. Med 2013, 19, 939-945. [PubMed: 23727931]

(14). Moon C; VanDussen KL; Miyoshi H; Stappenbeck TS Development of a Primary Mouse Intestinal Epithelial Cell Monolayer Culture System to Evaluate Factors That Modulate IgA Transcytosis. Mucosal Immunol 2013, 7, 818-828 [PubMed: 24220295] 
(15). Wang Y; DiSalvo M; Gunasekara DB; Dutton J; Proctor A; Lebhar MS; Williamson IA; Speer J; Howard RL; Smiddy NM; et al. Self-Renewing Monolayer of Primary Colonic or Rectal Epithelial Cells. Cell. Mol. Gastroenterol. Hepatol 2017, 4, 165-182. [PubMed: 29204504]

(16). Gracz AD; Ramalingam S; Magness ST Sox9 Expression Marks a Subset of CD24- Expressing Small Intestine Epithelial Stem Cells That Form Organoids in Vitro. AJP Gastrointest. Liver Physiol 2010, 298, G590-G600.

(17). Hubatsch I; Ragnarsson EGE; Artursson P Determination of Drug Permeability and Prediction of Drug Absorption in Caco-2 Monolayers. Nat. Protoc 2007, 2, 2111-2119. [PubMed: 17853866]

(18). Pawitan Y; Michiels S; Koscielny S; Gusnanto A; Ploner A False Discovery Rate, Sensitivity and Sample Size for Microarray Studies. Bioinformatics 2005, 21, 3017-3024. [PubMed: 15840707]

(19). Fallon JK; Neubert H; Hyland R; Goosen TC; Smith PC Targeted Quantitative Proteomics for the Analysis of 14 UGT1As and-2Bs in Human Liver Using NanoUPLC-MS/MS with Selected Reaction Monitoring. J. Proteome Res 2013, 12, 4402-4413. [PubMed: 23977844]

(20). Kailasam S; Frost K Rapid Method Development to Study Plasma Stability of Diverse Pharmaceutical Compounds Using Rapid Resolution LC and Triple Quadrupole MS https:// www.agilent.com/cs/library/applications/5990-4603EN.pdf (last accessed Apr 11, 2018).

(21). Love MI; Huber W; Anders S Moderated Estimation of Fold Change and Dispersion for RNASeq Data with DESeq2. Genome Biol 2014, 15, 550. [PubMed: 25516281]

(22). Benjamini Y; Hochberg Y Controlling the False Discovery Rate: A Practical and Powerful Approach to Multiple Testing. J. R. Stat. Soc. Ser. B Methodol 1995, 289-300.

(23). Cantor CR; Schimmel PR Biophysical Chemistry: Part III: The Behavior of Biological Macromolecules; Macmillan, 1980.

(24). Prasad AR; Prasad S; Nguyen H; Facista A; Lewis C; Zaitlin B; Bernstein H; Bernstein C Novel Diet-Related Mouse Model of Colon Cancer Parallels Human Colon Cancer. World J. Gastrointest. Oncol 2014, 6, 225. [PubMed: 25024814]

(25). Ubelmann F; Chamaillard M; El-Marjou F; Simon A; Netter J; Vignjevic D; Nichols BL; Quezada-Calvillo R; Grandjean T; Louvard D; et al. Enterocyte Loss of Polarity and Gut Wound Healing Rely upon the F-Actin-Severing Function of Villin. Proc. Natl. Acad. Sci 2013, 110, E1380-E1389. [PubMed: 23520048]

(26). Rao MC; Sarathy J; Sellin JH Intestinal Electrolyte Absorption and Secretion. In Sleisenger and Fordtran's Gastrointestinal and Liver Disease; Chapter 101; 2016; pp 1713-1735.

(27). Balda MS; Matter K Tight Junctions and the Regulation of Gene Expression. Biochim. Biophys. Acta BBA-Biomembr 2009, 1788, 761-767.

(28). Hartsock A; Nelson WJ Adherens and Tight Junctions: Structure, Function and Connections to the Actin Cytoskeleton. Biochim. Biophys. Acta BBA-Biomembr 2008, 1778, 660-669.

(29). Günzel D; Fromm M Claudins and Other Tight Junction Proteins. Compr. Physiol 2012, 2, 1819 1852. [PubMed: 23723025]

(30). Artursson P; Ungell A-L; Löfroth J-E Selective Paracellular Permeability in Two Models of Intestinal Absorption: Cultured Monolayers of Human Intestinal Epithelial Cells and Rat Intestinal Segments. Pharm. Res 1993, 10, 1123-1129. [PubMed: 8415396]

(31). McConnell EL; Liu F; Basit AW Colonic Treatments and Targets: Issues and Opportunities. J. Drug Target 2009, 17, 335-363. [PubMed: 19555265]

(32). Da Silva LC; Da Silva TL; Antunes AH; Rezende KR A Sensitive Medium-Throughput Method to Predict Intestinal Absorption in Humans Using Rat Intestinal Tissue Segments. J. Pharm. Sci 2015, 104, 2807-2812. [PubMed: 25690454]

(33). Nagare N; Damre A; Singh K; Mallurwar S; Iyer S; Naik A; Chintamaneni M Determination of Site of Absorption of Propranolol in Rat Gut Using in Situ Single-Pass Intestinal Perfusion. Indian J. Pharm. Sci 2010, 72, 625. [PubMed: 21694996]

(34). Yamaura Y; Chapron BD; Wang Z; Himmelfarb J; Thummel KE Functional Comparison of Human Colonic Carcinoma Cell Lines and Primary Small Intestinal Epithelial Cells for Investigations of Intestinal Drug Permeability and First-Pass Metabolism. Drug Metab. Dispos 2016, 44, 329-335. [PubMed: 26700954] 
(35). Wang X-X; Liu G-Y; Yang Y-F; Wu X-W; Xu W; Yang X-W Intestinal Absorption of Triterpenoids and Flavonoids from Glycyrrhizae Radix et Rhizoma in the Human Caco-2 Monolayer Cell Model. Molecules 2017, 22, 1627.

(36). Troutman MD; Thakker DR Rhodamine 123 Requires Carrier-Mediated Influx for Its Activity as a P-Glycoprotein Substrate in Caco-2 Cells. Pharm. Res 2003, 20, 1192-1199. [PubMed: 12948017]

(37). Faassen F; Vogel G; Spanings H; Vromans H Caco-2 Permeability, P-Glycoprotein Transport Ratios and Brain Penetration of Heterocyclic Drugs. Int. J. Pharm 2003, 263, 113-122. [PubMed: 12954186]

(38). Srivalli KMR; Lakshmi PK Overview of P-Glycoprotein Inhibitors: A Rational Outlook. Braz. J. Pharm. Sci 2012, 48, 353-367.

(39). Said HM Intestinal Absorption of Water-Soluble Vitamins in Health and Disease. Biochem. J 2011, 437, 357-372. [PubMed: 21749321]

(40). Yonezawa A; Inui K Novel Riboflavin Transporter Family RFVT/SLC52: Identification, Nomenclature, Functional Characterization and Genetic Diseases of RFVT/SLC52. Mol. Aspects Med 2013, 34, 693-701. [PubMed: 23506902]

(41). Yuasa H; Hirobe M; Tomei S; Watanabe J Carrier mediated Transport of Riboflavin in the Rat Colon. Biopharm. Drug Dispos 2000, 21, 77-82. [PubMed: 11100909]

(42). Sugano K; Kansy M; Artursson P; Avdeef A; Bendels S; Di L; Ecker GF; Faller B; Fischer H; Gerebtzoff G Coexistence of Passive and Carrier-Mediated Processes in Drug Transport. Nat. Rev. Drug Discov 2010, 9, 597. [PubMed: 20671764] 

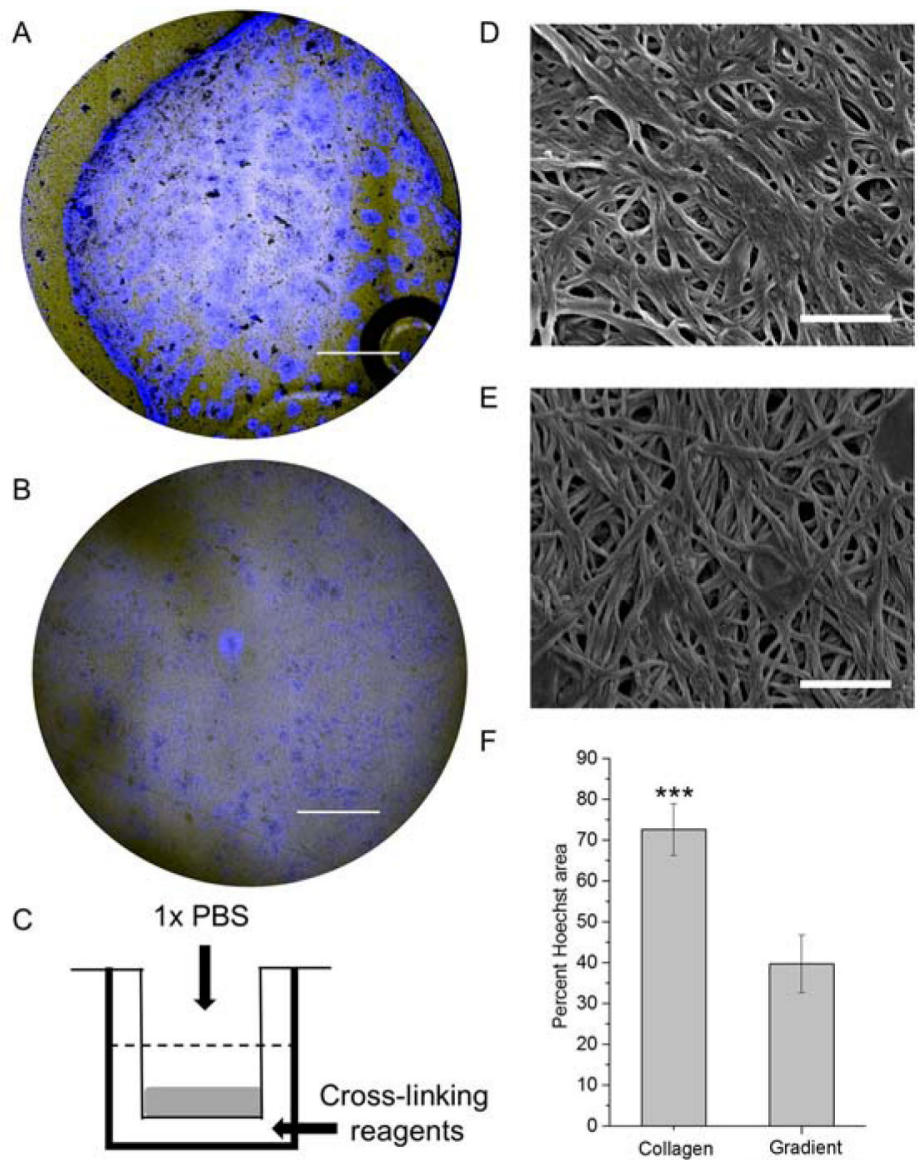

E
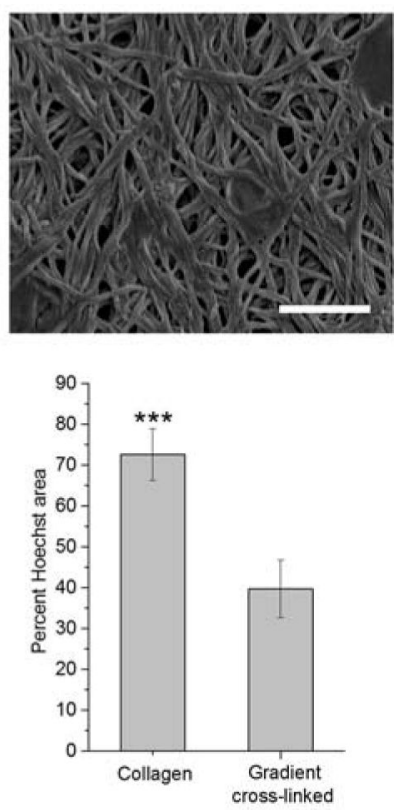

Figure 1.

Evaluation of collagen hydrogel scaffolds used for cell culture. Widefield Hoechst 33342 (blue) and brightfield-merged images of cells on A) non cross-linked collagen and B) collagen with a gradient of cross-linking. Delamination of the collagen layer is seen in the upper and lower left quadrants in "A". Scale bar $=2 \mathrm{~mm}$. C) Schematic of the gradient cross-linking process. D \& E) Electron microscopic images of the surface of non crosslinked collagen (D) and collagen with a gradient of cross-linking $(\mathrm{E})$. Scale bar $=1 \mu \mathrm{m}$. F) A comparison of colonic epithelial cell growth (2 days) on non cross-linked collagen and collagen with a gradient of cross-linking. 


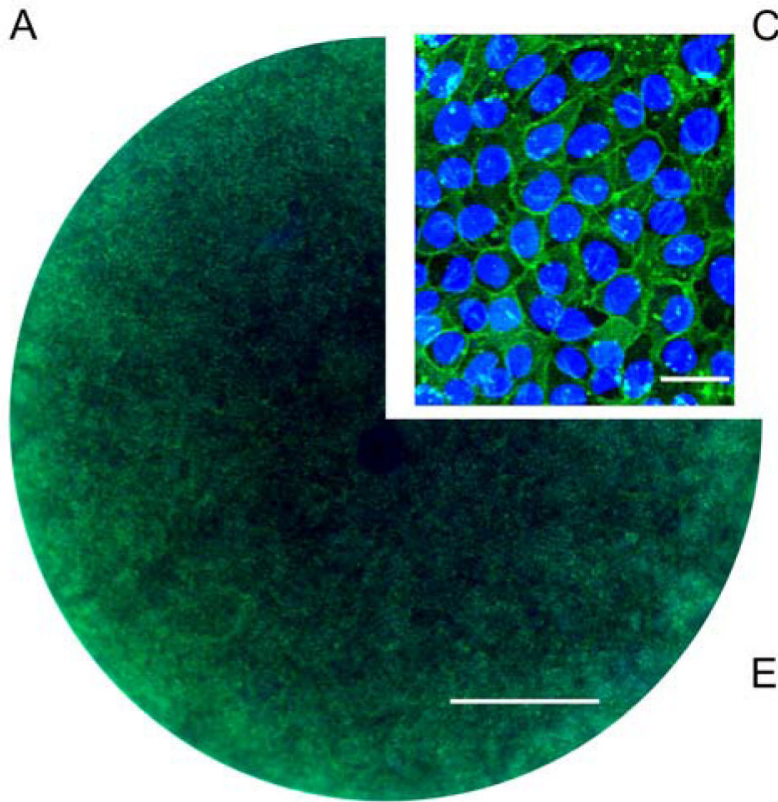

B

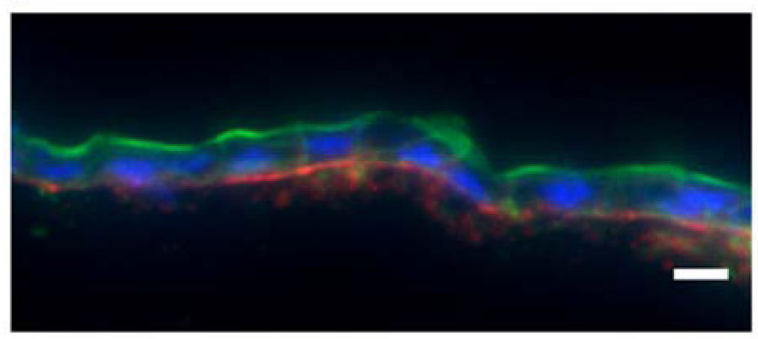

Actin/Integrin $\beta 4 /$ Hoechst

C

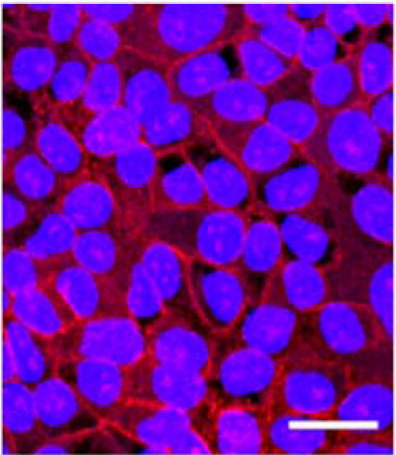

E-cadherin/Hoechst
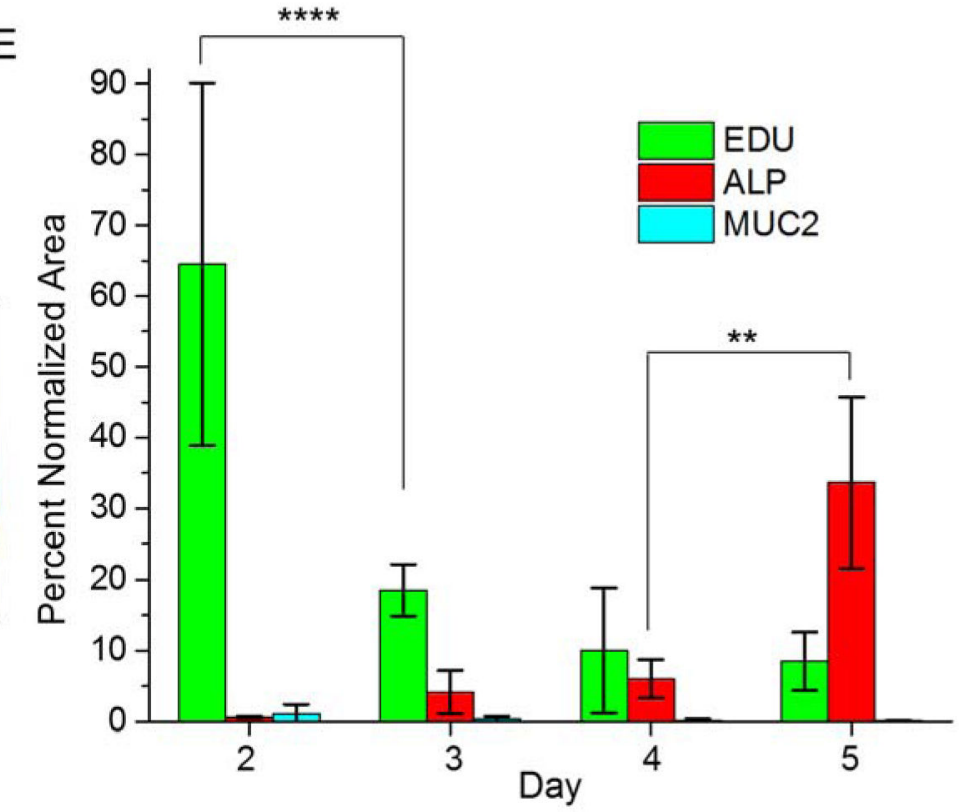

Figure 2.

Characterization of a colonic monolayers. A) Widefield and magnified images of a monolayer stained for F-actin (green) \& nuclei (blue). The scale bar is $2 \mathrm{~mm}$ and $10 \mu \mathrm{m}$ for widefield and magnified images respectively. B) Cross-sectioned monolayer stained for Factin (green), integrin $\beta 4$ (red) and nuclei (blue). The scale bar is $10 \mu \mathrm{m}$. C \& D) Staining of adherens junction protein, E-cadherin (red in $\mathrm{C}$ ) and tight junction protein, ZO-1 (red in D) and nuclei, Hoechst 33342 (blue). The scale bar for C \& D is $20 \mu \mathrm{m}$. E) Quantification of stained area for the different lineage markers over time as a percentage of the total Hoechst 33342-positive area. 
A
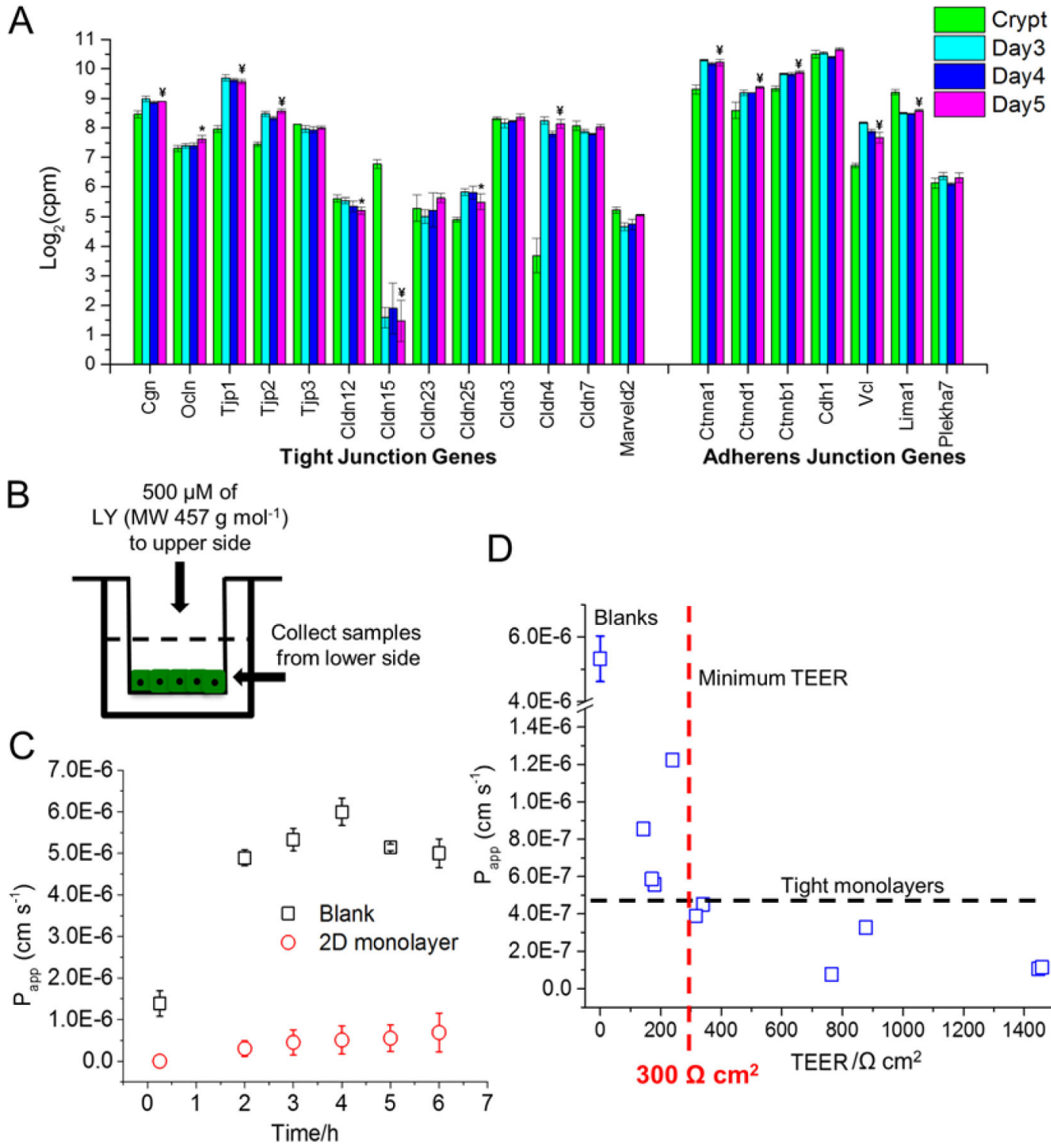

Figure 3.

Characterization of confluent monolayer integrity. A) Comparison of mRNA expression levels of tight and adherens junction genes over time. Statistical significance $\left(\mathrm{P}_{\mathrm{adj}}\right)$ between crypts and day 5 is shown with symbols as they were defined in methods. B) Experimental set up of LY permeability assay. C) Comparison of LY diffusion through colonic monolayers and a cellular cross-linked collagen scaffolds. D) LY permeability of the monolayer with respect to TEER. 
A

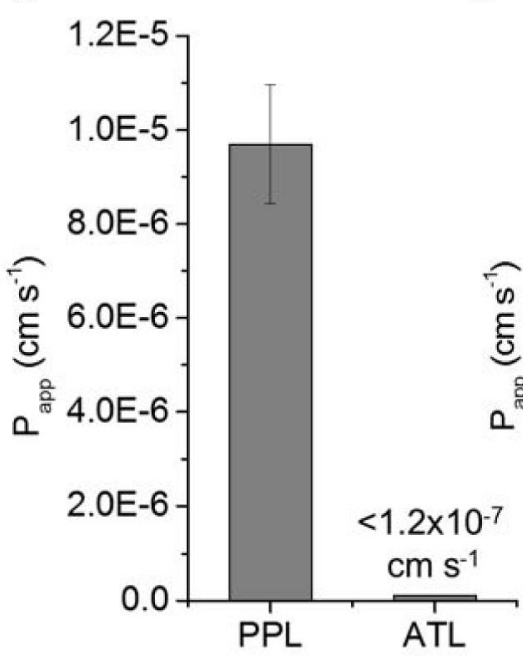

B

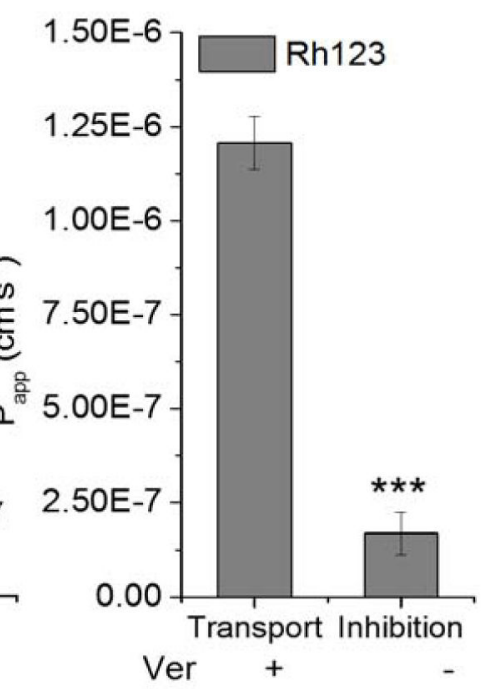

C

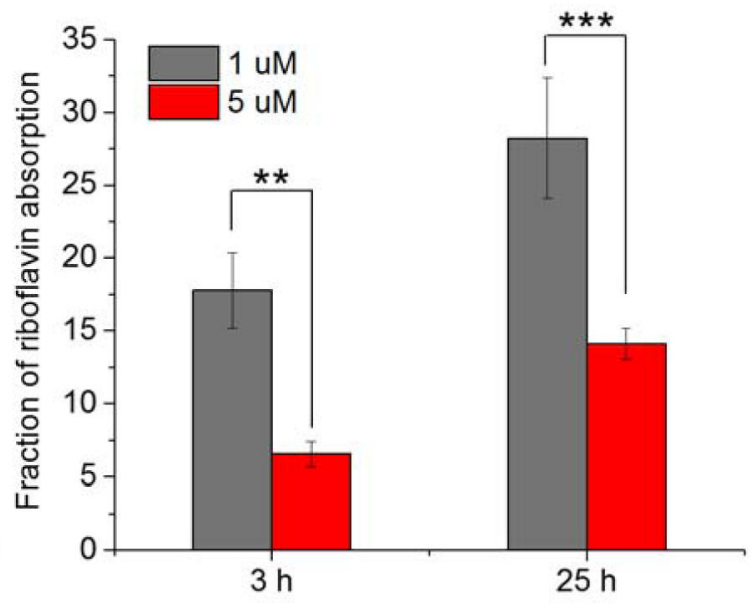

Figure 4.

Compound transport across the monolayer: A) Permeability of the monolayers to ATL and PPL. B) P-gp-based efflux secretory transport and inhibition. Rh123 $(10 \mu \mathrm{M})$ translocation through P-gp transporter and inhibition by verapamil $(200 \mu \mathrm{M})$. C) A comparison of fraction of absorption of riboflavin $(1 \mu \mathrm{M}$ and $5 \mu \mathrm{M})$ at $3 \mathrm{~h}$ and $25 \mathrm{~h}$. 
Table 1.

A comparison of mRNA and protein expression level of a selected set of transporters.

\begin{tabular}{|c|c|c|c|c|}
\hline Transporter & $\begin{array}{c}\text { Protein expression level in } \\
\text { monolayer }\end{array}$ & $\begin{array}{c}\text { Protein expression level in } \\
\text { crypts }\end{array}$ & $\begin{array}{c}\text { mRNA expression level in } \\
\text { monolayer }\end{array}$ & $\begin{array}{c}\text { mRNA expression level in } \\
\text { crypts }\end{array}$ \\
\hline P-gp/Abcb1a & +++ & +++++ & +++ & +++ \\
\hline BCRP/Abcg2 & + & + & ++ & ++ \\
\hline MRP1/Abcc1 & + & + & +++ & ++ \\
\hline MRP3/Abcc3 & + & ++ & +++ & +++ \\
\hline $\begin{array}{c}\text { NaK } \\
\text { ATPase/Atp1a1 }\end{array}$ & ++++ & ++++ & +++ \\
\hline
\end{tabular}

mRNA data was measured at day 5 of culture while protein was measured at day 6 of culture. Protein comparison levels in pmol $/ \mathrm{mg}$ membrane fraction protein $(\mathrm{PL})$ are $\mathrm{PL}>50(++++++) ; 17.5>\mathrm{PL}>15(+++++) ; 15>\mathrm{PL}>12.5(++++) ; 5>\mathrm{PL}>2.5(++) ; 2.5>\mathrm{PL}>0.1(+)$. mRNA expression comparison levels in counts per million (mRL) are $3<\mathrm{mRL}<4(++++) ; 2<\mathrm{mRL}<3(+++) ; 1<\mathrm{mRL}<2(++) ; 0.5<\mathrm{mRL}<1(+)$. 